\title{
Relação entre bem-estar no trabalho, valores pessoais e oportunidades de alcance de valores pessoais no trabalho
}

\section{Relations between work well-being, personal values and opportunities of achieving personal values at work}

\section{Fernanda Soraggi*}

Instituto de Educação Superior de Brasília - IESB, Brasília, DF,Brasil

\section{Tatiane Paschoal**}

Universidade de Brasília, UnB, Brasília, DF, Brasil

\begin{abstract}
RESUMO
Este estudo teve o objetivo de investigar o impacto dos valores pessoais e das oportunidades de alcance de valores pessoais no trabalho sobre o bemestar ocupacional de funcionários de organizações privadas. O bem-estar no trabalho é definido como a prevalência de emoções positivas no trabalho e a percepção do indivíduo de que, em seu trabalho, expressa e desenvolve suas habilidades e potenciais e avança no alcance de suas metas de vida. Aparentemente, a possibilidade do indivíduo alcançar valores pessoais importantes para ele em seu contexto ocupacional está relacionada ao bem estar no trabalho. Os principais resultados encontrados indicaram que os valores pessoais não são preditores do bem-estar no trabalho, mas que as oportunidades de interesses individuais têm impacto direto e significativo sobre o construto.

Palavras-chave: Felicidade, Afeto positivo, Afeto negativo, Metas no trabalho.
\end{abstract}

\begin{abstract}
The objective of this study was to investigate the impact on work well-being of personal values and opportunities of achieving personal values at work of private organizations' employees. Work well-being is defined as the predominance of positive emotions at work and as the perception of the person that, at work, expresses and develops his or her abilities and potentials and achieves his or her goals. Apparently, the possibility of the person to achieve important values at work is related with the work wellbeing. The most important results were that personal values by themselves are not predictors of work well-being. On the other hand, opportunities that express individual interests have direct and significant impact on the construct.
\end{abstract}

Keywords: Happiness, Positive affection, Negative affection, Work goals.

Tradicionalmente, o conceito de bem-estar está relacionado à ausência de doença ou à ausência de experiências negativas. Na 
literatura da Psicologia Organizacional, bem-estar tem sido relacionado à ausência de estresse ocupacional, burnout, depressão, esgotamento e outros construtos correlatos (ESTRAMIANA, 1992; KAHN; BYOSIERE, 1992; MASLACH; JACKSON, 1986; TAMAYO; TRÓCCOLI, 2002). As experiências negativas do trabalhador compõem a relação entre homem e trabalho e são fundamentais para a compreensão da identidade e da saúde do indivíduo. Autores diversos têm apontado o quanto patologias e sintomas físicos e mentais podem ser decorrentes de condições e organização do trabalho (ESTRAMIANA, 1992). A ausência de experiências negativas, por sua vez, não indica, necessariamente, a presença de experiências positivas (ALBUQUERQUE; TRÓCCOLI, 2004; WATSON; CLARK; TELLEGEN, 1988). É possível ter felicidade no trabalho? Que variáveis pessoais e organizacionais influenciam a felicidade e outras experiências positivas? Há necessidade de se investigar o bem-estar a partir da vivência de experiências positivas dos indivíduos.

Em geral, quando se fala em saúde, bem-estar e qualidade de vida no trabalho, não há uma clara distinção na definição desses termos e cada um deles é usado para explicar ou para definir o outro (FERREIRA et al., 2008). Na literatura científica, bem-estar e felicidade são, muitas vezes, usados como sinônimos. Apesar de os autores da Psicologia evitarem falar em felicidade e adotarem termos mais acadêmicos, como afeto e bem-estar, a tendência atual consiste em enfatizar as experiências positivas do sujeito (PASCHOAL, 2008; WARR, 2007).

De acordo com Ryan e Deci (2001), o conceito de bem-estar referese ao bom funcionamento psicológico e à experiência psicológica positiva. No entanto, esse não é um tema simples como pode parecer, mas um campo complexo e controverso, para o qual a atenção dispensada não é recente, datando desde a Grécia Antiga (SIQUEIRA; PADOVAM, 2008). Na área psicológica, o tema ganhou força especialmente a partir dos anos 60, com estudos sobre 0 crescimento pessoal e suas formas de promoção (RYAN; DECI, 2001). Nos estudos sobre o bem-estar geral, é possível destacar duas grandes correntes, que se diferem principalmente no que se refere à concepção da felicidade: o bem-estar subjetivo e o bem-estar psicológico (PASCHOAL; TAMAYO, 2008). A primeira, com tradição hedonista, entende o bem-estar como a presença de prazer, enquanto a segunda, com tradição eudaimônica, entende que o bemestar é, além da presença de prazer, também a realização do potencial humano e da verdadeira natureza de cada indivíduo (RYAN; DECI, 2001).

\section{Bem-estar subjetivo}

Para o filósofo grego Aristipo de Cirene, o objetivo de vida do homem é experienciar o máximo de prazer possível e a felicidade é a 
totalidade dos momentos hedônicos que ele possui (RYAN; DECI, 2001).

De acordo com a perspectiva hedônica, o bem-estar subjetivo inclui experiências de prazer e de desprazer com base em julgamentos que são feitos sobre os elementos positivos e negativos da vida. Ele corresponde a experiências internas do indivíduo, portanto, embora condições externas tenham importante influência sobre ele, elas não são inerentes ou necessárias e não o definem (ALBUQUERQUE; TRÓCCOLI, 2004).

Estudos sobre o bem-estar subjetivo identificaram três elementos que o compõem: afeto positivo, afeto negativo e satisfação com a vida. Os afetos positivo e negativo referem-se aos aspectos emocionais do bem-estar e a satisfação com a vida está relacionada ao aspecto cognitivo (DIENER et al., 1985). O afeto positivo é definido como um sentimento transitório, experimentado em determinado momento como um estado de alerta, entusiasmo e atividade, que gera um contentamento hedônico puro. O afeto negativo, também é definido como um sentimento transitório, no entanto, ele inclui emoções desagradáveis e sintomas psicológicos aflitivos e angustiantes. A satisfação com a vida, por sua vez, é um julgamento cognitivo, uma avaliação geral que a pessoa faz de sua própria vida e que depende da comparação entre as circunstâncias nas quais ela vive e os padrões escolhidos por ela (ALBUQUERQUE; TRÓCCOLI, 2004).

O bem-estar subjetivo não é a ausência de fatores negativos, mas a predominância dos afetos positivos sobre os negativos. De acordo com Diener e Lucas (apud SIQUEIRA; PADOVAM, 2008, p. 203), as análises de bem-estar estão muito mais relacionadas à frequência com que as experiências de afeto positivo acontecem do que com a intensidade dessas experiências. Desta forma, pode-se dizer que 0 bem-estar subjetivo consiste na presença de frequentes afetos positivos, na rara experiência de afetos negativos e na satisfação da pessoa com sua vida como um todo (ALBUQUERQUE; TRÓCCOLI, 2004).

\section{Bem-estar psicológico}

Aristóteles acreditava que a verdadeira felicidade estava na expressão das virtudes dos homens. Para ele, o objetivo do homem é viver de acordo com suas virtudes ou com seu verdadeiro self, que é quando ele expressa seus melhores potenciais (WATERMAN; SCHWARTZ; CONTI, 2008).

A eudaimonia refere-se a um bem-estar que é diferente da simples experiência de prazer (RYAN; DECI, 2001). Ela é um estado subjetivo e está relacionada aos sentimentos presentes quando o indivíduo se move para a autorrealização, desenvolvendo seus potenciais individuais e avançando em direção a seus propósitos de vida 
(WATERMAN; SCHWARTZ; CONTI, 2008). Para os teóricos do bemestar psicológico, a felicidade está centrada nas experiências de expressão pessoal e de autorrealização (PASCHOAL, 2008).

Segundo Ryff (1989), o bem-estar psicológico é definido a partir de seis dimensões que se associam aos diferentes desafios encontrados pelo indivíduo em sua busca pela autorrealização. Neste modelo, um indivíduo com alto bem-estar apresenta altos índices de atitudes positivas em relação a si mesmo (auto-aceitação), de satisfação e confiança em suas relações com os outros (relação positiva com os outros), de independência e autorregulação do comportamento (autonomia), de habilidades para escolher ou criar situações adequadas às condições pessoais (controle do ambiente), de senso de direção e de metas que contribuem para que ele perceba que a vida é significativa (propósito na vida) e de desenvolvimento de seu potencial e de sua expressão pessoal (crescimento pessoal).

Apesar de concordarem com a ênfase eudaimônica que Ryff propôs, para Ryan e Deci (2001), as seis dimensões usadas pela autora para definir o bem-estar psicológico podem ser, na verdade, antecedentes do construto.

Segundo Waterman, Schwartz e Conti (2008), a eudaimonia é uma condição suficiente, mas não necessária para a felicidade hedônica, isto é, existem várias coisas que o indivíduo deseja ter ou fazer que não envolvem o desenvolvimento de suas potencialidades individuais. Experiências de felicidade hedônica acontecem mais frequentemente que experiências de expressão pessoal e de autorrealização. A satisfação de necessidades físicas e sociais, por exemplo, gera afetos positivos e felicidade hedônica, mas não necessariamente a expressão e a realização pessoal (PASCHOAL, 2008).

Desta forma, o bem-estar pode ser entendido como um fenômeno multidimensional, que inclui em sua definição elementos hedônicos e eudaimônicos de felicidade. Isto é, o bem-estar é o estado afetivo do indivíduo e sua percepção de desenvolvimento de potenciais e de avanço nos propósitos de vida (WATERMAN, 1993).

\section{Bem-estar no trabalho}

Apesar da importância atual que o trabalho tem na vida do homem, observa-se que os estudos referentes ao bem-estar ocupacional ainda são escassos (PASCHOAL; TAMAYO, 2008). Concepções claras sobre esse assunto ainda não existem na literatura. Alguns estudiosos preferem representá-lo como a ausência de experiências negativas associadas ao burnout ou estresse e outros autores têm preferência por representá-lo como satisfação no trabalho, envolvimento e comprometimento organizacional (SIQUEIRA; PADOVAM, 2008).

Segundo Daniels (2000), o afeto tem se mostrado o aspecto mais relevante e central do bem-estar. Assim, o autor defende que ao se abordar o bem-estar no trabalho, deve-se considerar a experiência 
cumulativa de afetos vivenciados pelo trabalhador. A principal crítica feita à abordagem puramente hedonista de bem-estar é a de que ele não está restrito ao afeto no trabalho. Nesse sentido, há um esforço crescente nos últimos anos para conceituar o bem-estar no trabalho como um construto multidimensional, que engloba elementos eudaimônicos de felicidade, como a experiência subjetiva de realização e expressão pessoal, além de emoções e humores no trabalho (PASCHOAL, 2008; PASCHOAL; TAMAYO, 2008).

É importante salientar que a inclusão de elementos eudaimônicos na conceituação do bem-estar no trabalho pode levar a uma definição que mistura antecedentes e consequentes do construto (DANIELS, 2000; PASCHOAL; TAMAYO, 2008). Por exemplo, relações sociais positivas, autonomia e controle do ambiente, que consistem em dimensões do bem-estar psicológico propostas por Ryff (1989), podem ser consideradas antecedentes da experiência de felicidade.

Uma definição de bem-estar que inclui aspectos hedônicos e eudaimônicos, mas que evita misturar antecedentes e consequentes ou conceitos correlatos, foi proposta por Paschoal e Tamayo (2008). De acordo com os autores, o bem-estar no trabalho consiste na prevalência de emoções positivas no trabalho e na percepção do indivíduo de que ele expressa e desenvolve suas habilidades e potenciais e avança no alcance de suas metas de vida a partir do seu trabalho. Este é o conceito utilizado como referência no presente estudo. Ele aborda claramente as experiências positivas do trabalhador por meio de emoções e humores positivos e realização e expressão pessoal.

Para pesquisadores e gestores do campo organizacional interessa conhecer as características individuais e contextuais que interferem na experiência de bem-estar do trabalhador. A literatura científica aponta que os elementos do próprio contexto ocupacional parecem ter importante influência sobre o bem-estar no trabalho, como clima social, percepção de justiça e suporte organizacional (MOURÃO, 2009; PASCHOAL, 2008; SOBRINHO, 2008). Apesar deste aparente impacto sobre o bem-estar no trabalho, variáveis pessoais também podem ser seus preditores. Jex e Spector (1996) identificaram a relação entre afetividade negativa e ansiedade no trabalho e Wiese e Freund (2005) identificaram que o alcance de metas têm impacto positivo sobre a percepção de sucesso dos trabalhadores sobre seu bem-estar no trabalho.

Entretanto, alguns autores alertam para a importância de se investigar a interação entre variáveis individuais e situacionais, uma vez que o bem-estar no trabalho não depende apenas de variáveis pessoais ou de variáveis do ambiente, mas sim da combinação de ambas (DESSEN, 2005; PAZ, 2004; WARR, 2007). Esta, porém, ainda é uma questão pouco investigada empiricamente. 
Muitos estudos e propostas teóricas para o desenvolvimento do construto do bem-estar no trabalho são recentes (DANIELS, 2000; PASCHOAL; TAMAYO, 2008; WARR, 2007). Além disso, os estudos sobre bem-estar ocupacional abordam principalmente as emoções e humores do trabalhador, que consistem na dimensão hedônica do bem-estar (BARSKY; KAPLAN, 2007). A expressão pessoal e a realização no trabalho, que constituem os elementos eudaimônicos do fenômeno, não costumam ser consideradas nas pesquisas e, portanto, poucas conclusões podem ser traçadas a respeito de seus antecedentes.

A fim de contribuir para o preenchimento dessa lacuna, o presente estudo tem o objetivo de investigar o impacto dos valores pessoais e das oportunidades de alcance de valores pessoais no trabalho sobre o bem-estar ocupacional. A seguir, são apresentadas as variáveis independentes do estudo: valores pessoais e oportunidades de alcance de valores pessoais no trabalho.

\section{Valores pessoais e oportunidades de alcance de valores pessoais no trabalho}

Os valores pessoais relacionam-se com as atitudes das pessoas, referem-se aos princípios que as orientam e podem ser usados para explicar as diferenças individuais (ROS, 2001). O que diferencia um valor dos outros é o tipo de motivação que cada um expressa (TAMAYO, 2007). Em nível individual, os valores são as metas do indivíduo, que guiam suas avaliações e seus comportamentos, isto é, são metas motivacionais que expressam os alvos que a pessoa deseja atingir na vida (SCHWARTZ, 2005). Desta forma, não estão restritos a situações específicas e se ordenam de acordo com a sua importância.

Por meio de pesquisas transculturais, Schwartz (1992; 2001) elaborou um modelo dinâmico, considerado universal, de estrutura motivacional composto por dez tipos motivacionais. Os tipos motivacionais são, segundo Tamayo (1994), fatores que se compõem por vários valores similares quanto ao seu conteúdo motivacional.

Os dez tipos motivacionais propostos por Schwartz em seu modelo são: 1) hedonismo: busca pelo prazer e pela gratificação, em oposição à dor e ao sofrimento; 2) realização: busca pelo sucesso pessoal e pelo reconhecimento social, por meio da demonstração das competências; 3) poder: busca pelo prestígio, pela preservação do status social e pelo controle e domínio sobre as pessoas e os recursos; 4) autodeterminação: busca por autonomia e pela independência de pensamento e ação; 5) estimulação: busca por desafios, novidades e mudanças na vida; 6) conformidade: controle de impulsos, de tendências e de comportamentos em favor de expectativas sociais; 7) benevolência: preocupação com o bem-estar de pessoas próximas; 8 ) tradição: respeito e aceitação de ideias e de 
costumes tradicionais da sociedade; 9) segurança: busca pela integridade e pela estabilidade pessoal e da sociedade; e 10) universalismo: compreensão, aceitação e tolerância para com os outros e preocupação com o bem-estar de todos.

Essa estrutura motivacional é dinâmica e seus componentes vinculam-se por meio de diversas polaridades, em relações de compatibilidade e de conflito entre si (TAMAYO, 1994). Isso acontece porque alguns tipos motivacionais servem a interesses individuais (hedonismo, realização, poder, autodeterminação e estimulação), outros tipos servem a interesses coletivos (conformidade, benevolência e tradição) e outros, a interesses mistos (segurança e universalismo). Desta forma, buscar por um tipo motivacional pode gerar consequências compatíveis ou conflitantes com a busca por outro tipo (SCHWARTZ, 1992).

As oposições entre os tipos motivacionais podem ser organizadas em duas dimensões bipolares superiores, sendo a primeira abertura à mudança versus conservação e a segunda autopromoção versus autotranscendência (SCHWARTZ, 2005). Na primeira dimensão, o pólo abertura à mudança abrange os tipos motivacionais hedonismo, estimulação e autodeterminação e refere-se à motivação do indivíduo em seguir seus próprios interesses intelectuais e afetivos por meio de caminhos incertos e ambíguos. Já o pólo conservação, cujos tipos motivacionais são segurança, conformidade e tradição, refere-se à motivação do indivíduo em procurar estabilidade e em preservar o status quo e a segurança gerada por ele na relação com os outros. $O$ pólo autopromoção, da segunda dimensão, agrupa os tipos motivacionais poder e realização e expressa a motivação do indivíduo em promover seus próprios interesses, enquanto 0 pólo autotranscendência reúne os tipos motivacionais universalismo e benevolência e baseia-se na motivação do indivíduo em promover o bem-estar dos outros e da natureza, transcendendo suas preocupações egoístas (SCHWARTZ, 2005).

Apesar de não existirem justificativas consistentes na literatura sobre a possível relação causal entre valores e bem-estar, pesquisas têm apontado para a possibilidade de a experiência de felicidade de um indivíduo estar relacionada diretamente com as suas motivações (DIENER et al., 1999). Para Saving e Schwartz (2000), os valores influenciam percepções, atitudes e comportamentos favoráveis à felicidade e à satisfação com a vida, o que contribui para o bemestar.

A relação entre valores e bem-estar ocupacional parece residir na possibilidade do indivíduo alcançar ou não valores importantes para ele em seu contexto de trabalho (PASCHOAL, 2008). Assim, uma forma interessante de a organização valorizar seu empregado pode ser a oferta de oportunidades para que ele atinja suas metas pessoais por meio de seu trabalho (TAMAYO; PASCHOAL, 2003). 
As oportunidades no trabalho são, segundo Paschoal (2008), condições ou características do trabalho, determinadas pela organização, que são percebidas pelo trabalhador e que podem se constituir em oportunidades para o alcance dos valores pessoais. Elas podem ser divididas em duas categorias: oportunidades que expressam interesses individuais (oportunidades de abertura à mudança e de autopromoção) e oportunidades que expressam interesses coletivos e mistos (oportunidades de conservação e de autotranscendência). As oportunidades de interesses individuais são definidas em termos de características que possibilitam ações e pensamentos independentes do trabalhador e que refletem condições de favorecimento da expressividade pessoal e do desenvolvimento dos potenciais individuais no trabalho. As oportunidades de interesses coletivos e mistos são definidas como características que possibilitam a proteção da estabilidade, a preservação de práticas tradicionais de trabalho e o favorecimento do bem-estar dos outros e do meio ambiente (PASCHOAL, 2008).

Paschoal (2008) investigou o impacto dos valores e das oportunidades de alcance de valores pessoais no trabalho sobre 0 bem-estar ocupacional. Em seu estudo, os valores não apresentaram relação significativa com o bem-estar, porém as oportunidades de alcance de valores pessoais no trabalho influenciaram os afetos positivo e negativo e a realização do trabalhador. Paschoal (2008) identificou que as oportunidades de interesses individuais tiveram influência forte e positiva sobre o afeto positivo e a realização e influência mais fraca e negativa sobre o afeto negativo.

É importante salientar que os dados foram coletados por Paschoal (2008) entre servidores de uma organização pública do Distrito Federal, onde todos possuem normas claras de trabalho e estabilidade. A autora aponta que uma das principais limitações da pesquisa foi o fato de os resultados não poderem ser facilmente generalizáveis. Assim, a aplicação do mesmo estudo em organizações privadas, de diversas regiões, com práticas e políticas diferentes daquelas pertinentes ao setor público, pode apresentar diferentes resultados no que se refere ao impacto dos valores pessoais e das oportunidades sobre o bem-estar no trabalho.

No presente estudo, a relação entre valores, oportunidades e bemestar no trabalho foi testada entre empregados de empresas privadas diversas, situadas no Distrito Federal e em Minas Gerais. Os objetivos específicos do estudo foram: a) testar o impacto dos quatro pólos das dimensões superiores de valores pessoais sobre o bem-estar no trabalho e b) testar o impacto das oportunidades de alcance de valores que expressam interesses individuais e que expressam interesses coletivos e mistos sobre o bem-estar no trabalho. 


\section{Método}

\section{Amostra}

Participaram do estudo 121 trabalhadores de empresas privadas. Dentre eles, 82 eram de organizações do Distrito Federal e 39 pertenciam ao quadro de uma organização de Minas Gerais.

Quanto aos dados sócio-demográficos da amostra, $52,10 \%$ dos participantes eram homens e $47,90 \%$ eram mulheres. A média de idade da amostra foi de 29,60 anos $(\mathrm{dp}=9,19)$ e o tempo de serviço médio foi de 3,47 anos ( $d p=4,86)$. Em relação ao estado civil, $57,85 \%$ eram solteiros, $38,02 \%$ casados, $2,48 \%$ separados ou divorciados e $1,65 \%$ viviam em união estável. A maioria dos sujeitos $(48,76 \%)$ tinha Ensino Superior incompleto, seguida pelos que haviam concluído o Ensino Superior $(28,10 \%)$ e pelos que tinham Pós-graduação $(19,01 \%)$. A escolaridade mais baixa da amostra foi 0 Ensino Médio completo (4,13\%).

\section{Instrumentos}

Neste estudo foi utilizado um questionário composto por três instrumentos: Escala de Bem-estar no Trabalho (EBET), Questionário de Perfis de Valores (QPV) e Medidas de Oportunidades no Trabalho.

a) Escala de Bem-estar no Trabalho (EBET)

A EBET é o instrumento utilizado para avaliar a variável dependente do estudo. Ela foi construída e validada por Paschoal e Tamayo (2008) com os objetivos de operacionalizar as dimensões hedônica e eudaimônica do bem-estar no trabalho e de enfocar as vivências do trabalhador a fim de evitar a consideração de possíveis antecedentes do construto.

A escala é composta por 30 itens divididos em três fatores: afeto positivo (9 itens e alpha de Cronbach - $\alpha-0,92$ ), afeto negativo ( 12 itens e $\alpha$ de 0,89 ) e realização (9 itens e $\alpha$ de 0,91). Nos primeiros 21 itens, referentes ao afeto, o respondente deve avaliar a afirmativa "nos últimos seis meses, meu trabalho tem me deixado..." a partir de uma escala de respostas que varia de "nem um pouco" (1) a "extremamente" (5). Exemplos de itens são "contente", "animado", "frustrado" e "ansioso". Nos últimos 9 itens, sobre realização, o respondente deve avaliar o quanto as afirmações representam suas opiniões sobre o trabalho, com escala de respostas variando de "discordo totalmente" (1) a "concordo totalmente" (5). Exemplos de itens são "neste trabalho realizo meu potencial" e "neste trabalho supero desafios".

b) Questionário de Perfis de Valores (QPV)

Para a mensuração da variável independente valores pessoais, foi utilizado o Questionário de Perfis de Valores traduzido para o português e validado por Porto (2005). Os itens deste instrumento basearam-se na teoria de valores de Schwartz (1992) e foram desenvolvidos a partir das definições conceituais do Inventário de 
Valores de Schwartz (SVS), validado no Brasil por Tamayo e Schwartz (1993).

O instrumento é composto por 40 itens com retratos verbais de pessoas que descrevem metas e desejos. Para cada um dos itens, 0 respondente deve avaliar a questão "quanto essa pessoa se parece com você?", a partir de uma escala de resposta de 5 pontos que variam desde o "não se parece nada comigo" (1) até o "se parece muito comigo" (5).

Neste estudo, foram considerados os quatro pólos das dimensões superiores: abertura à mudança ( $\alpha$ de 0,74$)$, conservação ( $\alpha$ de $0,74)$, autopromoção $(\alpha$ de 0,75$)$ e autotranscedência ( $\alpha$ de 0,80 ).

c) Medida de Oportunidades no Trabalho

O instrumento utilizado para avaliar a variável independente oportunidades de alcance de valores pessoais no trabalho foi desenvolvido por Paschoal (2008). Os 16 itens do instrumento foram baseados nas quatro dimensões de segunda ordem de Schwartz (1992) e avaliam dois tipos de oportunidades: oportunidades de interesses individuais ( 10 itens e $\alpha$ de 0,88 ) e oportunidades de interesses coletivos e mistos ( 6 itens e $\alpha$ de 0,55). Para cada um dos itens, o participante deve responder a afirmativa "neste trabalho, tenho oportunidades de...", com escala de respostas que varia de "nenhuma" (1) a "muita" (4). Exemplos de itens da escala são "exercer minha criatividade" e "ter estabilidade".

\section{Procedimento}

O questionário foi precedido por uma folha de rosto contendo uma carta explicativa com os objetivos do estudo, a confidencialidade das informações prestadas e o termo de consentimento do participante, além dos contatos para informações.

Dentre os trabalhadores do Distrito Federal, uma parte dos questionários foi aplicada individualmente no contexto de uma microempresa. Outra parte foi aplicada individualmente e coletivamente em trabalhadores de diferentes empresas privadas que faziam cursos de graduação ou especialização em uma instituição de Ensino Superior. Nesta situação, os questionários foram aplicados na própria instituição de ensino, durante os intervalos dos cursos. Todos os respondentes trabalhavam em empresas privadas do Distrito Federal. Em ambos os casos, a aplicação foi realizada pela pesquisadora, que recebia os questionários em um envelope. Na empresa de Minas Gerais, um responsável pelo departamento de Recursos Humanos e colaborador na coleta de dados distribuiu os questionários a 103 funcionários da organização, que deveriam preenchê-los e devolvêlos em envelopes lacrados. Do total de 103 questionários, 39 foram devolvidos. 


\section{Análise de dados}

Os dados foram analisados por meio de análises descritivas (média, desvio padrão e valores mínimo e máximo), correlação bivariada de Pearson e regressão múltipla linear padrão.

\section{Resultados}

\section{Análise descritiva}

Quanto à análise descritiva da variável dependente bem-estar no trabalho, a média encontrada, em uma escala de 1 a 5 , para o afeto positivo foi de $3,10(\mathrm{dp}=0,85)$, para o afeto negativo de $2,08(\mathrm{dp}=$ $0,70)$ e para a realização de $3,53(\mathrm{dp}=0,78)$.

Em relação à variável independente valores pessoais, para a amostra estudada, os tipos motivacionais mais importantes encontrados foram autodeterminação $(M=4,08 ; d p=0,56)$, benevolência $(M=4,05$; $\mathrm{dp}=0,58)$ e universalismo $(M=3,92 ; \mathrm{dp}=0,60)$ enquanto os menos importantes foram estimulação $(M=3,35 ; d p=0,84)$, tradição $(M=2,90 ; d p=0,64)$ e poder $(M=2,74 ; d p=0,78)$. Estes dados são compatíveis com a ordem hierárquica dos tipos motivacionais proposta por Schwartz (2005), na qual benevolência, autodeterminação e universalismo são os tipos motivacionais mais importantes e poder, tradição e estimulação são os tipos menos importantes. Quanto às dimensões de segunda ordem, observou-se que a dimensão mais importante para a amostra estudada foi autotranscendência $(M=3,97 ; d p=0,54)$ e a menos importante foi autopromoção $(M=3,16 ; d p=0,67)$.

Para a análise descritiva da variável independente oportunidades de alcance de valores pessoais no trabalho, os resultados apontam que as oportunidades de interesses coletivos e mistos (oportunidades de conservação e de autotranscendência) receberam maior pontuação $(\mathrm{M}=3,18 ; \mathrm{dp}=0,41)$ e as oportunidades de interesses individuais (oportunidades de abertura à mudança e de autopromoção) receberam pontuação mais baixa $(M=3,03 ; d p=0,58)$.

\section{Correlações}

Foram verificadas as correlações entre cada fator do bem-estar no trabalho e as variáveis independentes do estudo. Os resultados são apresentados na Tabela 1. 
Tabela 1. Correlações entre os fatores do bem-estar e as variáveis independentes

\begin{tabular}{lccc}
\hline \multicolumn{1}{c}{ Variável } & Afeto positivo & Afeto negativo & Realização \\
\hline $\begin{array}{l}\text { Oportunidades de } \\
\text { interesses individuais }\end{array}$ & $0,621^{* *}$ & $-0,283^{* *}$ & $0,746^{* *}$ \\
$\begin{array}{l}\text { Oportunidades de } \\
\text { interesses coletivos e }\end{array}$ & $0,322^{* *}$ & $-0,246^{* *}$ & $0,379^{* *}$ \\
mistos & 0,146 & $-0,055$ & 0,102 \\
Abertura à mudança & $0,276^{* *}$ & $-0,104$ & $0,242^{* *}$ \\
Conservação & 0,132 & 0,015 & $0,226^{*}$ \\
Autopromoção & $0,217^{*}$ & $-0,196^{*}$ & 0,155 \\
Autotranscendência & & &
\end{tabular}

A variável oportunidades de alcance de valores pessoais no trabalho apresentou correlações significativas com os três fatores do bemestar no trabalho, tanto no que se refere às oportunidades de interesses individuais, quanto às oportunidades de interesses coletivos e mistos. As correlações entre as oportunidades de interesse individuais e afeto positivo e realização foram positivas e fortes e as correlações das oportunidades de interesses coletivos e mistos com estes fatores, apesar de também positivas, foram moderadas. As correlações de ambas variáveis com o afeto negativo, apesar de significativas, foram mais fracas e negativas.

Em relação a variável valores pessoais, o tipo motivacional abertura à mudança não apresentou correlação significativa com nenhum dos fatores do bem-estar no trabalho. O tipo motivacional conservação apresentou correlação significativa positiva fraca com afeto positivo ( $r$ $=0,276)$ e com realização $(r=0,242)$, mas não apresentou correlação significativa com afeto negativo. O tipo autopromoção apresentou correlação significativa apenas com o fator realização $(r=$ $0,226)$, sendo a mesma positiva, porém fraca, e o tipo autotranscendência apresentou correlação significativa apenas com afeto positivo $(r=0,217)$ e afeto negativo $(r=-0,196)$. De forma geral, as correlações entre valores e bem-estar no trabalho foram fracas.

\section{Regressões}

A regressão múltipla linear padrão foi conduzida com o objetivo de verificar qual o efeito que cada variável independente tem sobre os três fatores da variável dependente (afeto positivo, afeto negativo e realização). Os resultados das regressões para cada um dos fatores estudados são apresentados na Tabela 2 com os coeficientes de regressão não padronizados (B), os coeficientes de regressão padronizados $(\beta)$, o coeficiente de correlação $(R)$, o coeficiente de 
determinação $\left(R^{2}\right)$ e o coeficiente de determinação ajustado $\left(R^{2}\right.$ ajustado).

Tabela 2. Regressão múltipla linear padrão dos valores pessoais e das oportunidades de alcance de valores sobre os três fatores do bem-estar no trabalho

\begin{tabular}{|c|c|c|c|c|c|c|}
\hline \multirow{2}{*}{ Variáveis preditoras } & \multicolumn{2}{|c|}{ Afeto Positivo } & \multicolumn{2}{|c|}{ Afeto Negativo } & \multicolumn{2}{|c|}{ Realização } \\
\hline & $B$ & $\beta$ & $B$ & $\beta$ & $B$ & $\beta$ \\
\hline $\begin{array}{l}\text { Oportunidades de } \\
\text { interesses individuais }\end{array}$ & $0,92 * * *$ & 0,62 & $-0,33^{*}$ & $-0,27$ & $0,99 * * *$ & 0,74 \\
\hline $\begin{array}{l}\text { Oportunidades de } \\
\text { interesses coletivos e }\end{array}$ & $-0,02$ & $-0,01$ & $-0,21$ & $-0,12$ & $-0,02$ & $-0,01$ \\
\hline Abertura à mudança & 0,07 & 0,04 & 0,01 & 0,01 & $-0,04$ & $-0,03$ \\
\hline Conservação & 0,19 & 0,11 & 0,15 & 0,11 & $-0,15$ & $-0,10$ \\
\hline Autotranscendência & 0,09 & 0,05 & $-0,27$ & $-0,21$ & 0,01 & 0,01 \\
\hline \multirow[t]{2}{*}{ Autopromoção } & $-0,12$ & $-0,09$ & 0,15 & 0,14 & $-0,02$ & $-0,02$ \\
\hline & \multicolumn{2}{|c|}{$\begin{array}{c}R^{2}=0,42 \\
R^{2} \text { aiustado }=0,39 \\
R=0,65\end{array}$} & \multicolumn{2}{|c|}{$\begin{array}{c}R^{2}=0,14 \\
R^{2} \text { aiustado }=0,09 \\
R=0,37\end{array}$} & \multicolumn{2}{|c|}{$\begin{array}{c}R^{2}=0,57 \\
R^{2} \text { aiustado }=0,54 \\
R=0,75\end{array}$} \\
\hline
\end{tabular}

Os valores de $\mathrm{R}$ para os três fatores do bem-estar no trabalho foram significativamente diferente de zero, sendo para o afeto positivo $F(6,121)=13,762, p<0,001$, para o afeto negativo $F(6,121)=2,998$, $p<0,001$ e para realização $F(6,121)=24,946, p<0,001$.

Para os três fatores do bem-estar no trabalho, apenas a variável oportunidades de interesses individuais apresentou resultados significativos. Esta variável explica $42 \%$ do afeto positivo e $57 \%$ da realização, indicando que, quanto maiores são as oportunidades de alcance de valores pessoais relacionados a interesses individuais, maior é o afeto positivo e a realização no trabalho. Em relação ao afeto negativo, a variável explica $14 \%$ do mesmo, porém a relação foi negativa, o que indica que, quanto maiores as oportunidades de alcance de valores pessoais que expressam interesses individuais no trabalho, menor é o afeto negativo.

\section{Discussão}

Este estudo teve como objetivo investigar o impacto dos valores pessoais e das oportunidades de alcance de valores pessoais no trabalho sobre o bem-estar ocupacional. Bem-estar foi definido como a prevalência de emoções positivas e percepção de realização pessoal e alcance de metas pessoais no trabalho. Foram abordados, além do afeto negativo, o afeto positivo e a realização e expressão pessoal do trabalhador, que representam experiências claramente positivas.

De acordo com Saving e Schwatrz (2000), a ligação entre valores e bem-estar depende da compatibilidade entre os valores pessoais e os valores do contexto no qual o indivíduo está inserido. Assim, é mais 
provável que as pessoas apresentem alto bem-estar quando estão em um contexto em que podem expressar e realizar seus valores. Silva (2007) apontou que a similaridade entre a hierarquia de valores pessoais do trabalhador e a hierarquia de valores organizacionais percebidos pelos empregados aumenta o bem-estar no trabalho, enquanto divergências entre essas hierarquias o diminui.

$\mathrm{Na}$ amostra pesquisada, os resultados das correlações e das regressões indicaram que os valores pessoais dos trabalhadores, por si só, não são preditores do bem-estar no trabalho, uma vez que estas variáveis apresentaram correlações fracas e índices de regressões não significativos.

Em relação às oportunidades de alcance de valores pessoais no trabalho, as oportunidades de interesses individuais tiveram impacto direto e significativo sobre o afeto positivo e a realização, explicando, sozinhas, $42 \%$ do afeto positivo e $57 \%$ da realização. Isso indica que um contexto que ofereça possibilidades de autonomia, pensamento criativo e reconhecimento e prestígio social pode aumentar significativamente a felicidade do trabalhador e, consequentemente, seu bem-estar no trabalho. Este resultado vai ao encontro das tendências atuais em gestão de pessoas, segundo as quais as organizações têm investido não apenas no desenvolvimento profissional do trabalhador, como também em seu desenvolvimento pessoal. Há a preocupação na valorização dos empregados e na criação de condições de trabalho necessárias para 0 bom desempenho e a satisfação do trabalhador (PASCHOAL, 2008).

Para Tamayo e Paschoal (2003), o trabalho é, por natureza, uma estratégia de realização pessoal dos indivíduos. Savig, Roccas e Halevy (2005) apontam que os ambientes de trabalho são contextos nos quais os indivíduos encontram oportunidades ou restrições ao alcance de seus valores e metas pessoais. Desta forma, é de se esperar que organizações com maiores índices de bem-estar ocupacional tenham características e condições de trabalho que ofereçam oportunidades e possibilidades de ação para seus colaboradores alcançarem suas metas pessoais (PASCHOAL, 2008).

Os preditores das experiências positivas no trabalho parecem ser diferentes dos preditores das experiências negativas neste contexto. As oportunidades de alcance de valores que expressam interesses individuais explicam muito mais os fatores afeto positivo e realização do bem-estar no trabalho do que o fator afeto negativo. Este resultado, que é compatível com os resultados encontrados em organizações públicas por Paschoal (2008), sustenta a importância de se enfatizar as experiências positivas nos estudos organizacionais, em detrimento de estudos que enfoquem apenas as experiências negativas ou a ausência delas.

Neste sentido, este estudo tem uma importante contribuição para a literatura da área, uma vez que abordou o tema do bem-estar a 
partir de vivências positivas do trabalhador. Contribuiu também para a melhor compreensão do bem-estar no trabalho como um conceito multidimensional, que inclui aspectos hedônicos e eudaimônicos da felicidade, ou seja, possui tanto componentes afetivos (emoções e humores), como também a percepção de expressão pessoal e de realização no trabalho. A dimensão hedônica do bem-estar no trabalho tem sido mais bem explorada na literatura organizacional. As emoções e os humores no contexto laboral contam com razoável número de testes empíricos e esforços teóricos de análise de conteúdo e diferenciação de construtos correlatos. A dimensão da realização e expressão no trabalho, por sua vez, ainda é pouco estudada. Além disso, este estudo replicou uma pesquisa anterior (PASCHOAL, 2008) e procurou explorar uma de suas limitações, tendo sido conduzido em uma amostra diferenciada.

Apesar de ter atingido os objetivos propostos e de ter oferecido contribuições ao campo do bem-estar no trabalho, algumas limitações do presente estudo podem ser apontadas. Em primeiro lugar, destaca-se o fato de o questionário ter sido aplicado por um empregado da própria empresa na organização de Minas Gerais. Isso pode ter contribuído para uma maior desejabilidade social por parte dos respondentes, o que afetaria os resultados encontrados. Outra limitação neste estudo é o baixo índice de confiabilidade do fator oportunidades de alcance de valores pessoais no trabalho que expressam interesses coletivos e mistos. Estudos futuros devem revisar e aprofundar o conteúdo do construto, testando empiricamente sua estrutura.

Além disso, há desafios e questões que permanecem. Um desafio diz respeito à própria definição e operacionalização do construto do bemestar no trabalho. A consideração de uma dimensão afetiva e de uma dimensão correspondente à realização e expressão pessoal parece ser adequada. Afeto positivo e realização compõem o bem-estar ou felicidade do trabalhador. Por outro lado, podem insuficientes para contemplar todo o fenômeno.

Uma questão importante diz respeito ao aprofundamento do construto com amostras que representem as mudanças que vêm ocorrendo na força de trabalho brasileira. Os dados da presente pesquisa foram coletados entre trabalhadores formais de empresas privadas. O trabalho geralmente se realiza em um contexto social e, muitas vezes, formal, como é o caso das organizações. No entanto, o emprego em organizações amplas e formais é aquele que vem sofrendo maior redução no mercado de trabalho.

Segundo Antunes e Alves (2004), o emprego estável tem cedido espaço para as formas não regulamentadas de trabalho. O número de trabalhadores informais e terceirizados tem aumentado consideravelmente nos últimos anos. $O$ mundo do trabalho contemporâneo tem sido marcado também pela crescente exclusão 
de jovens que atingiram a idade de ingresso no mercado de trabalho e de pessoas com mais de 40 anos de idade (ANTUNES; ALVES, 2004). Essas pessoas passam a se somar aos desempregados, aos contingentes de trabalho precário e a trabalhadores voluntários. A expansão dos estudos para as formas e os contextos alternativos de trabalho indica um caminho a ser seguido no campo do bem-estar laboral.

Vale ressaltar também o viés cultural que a definição da felicidade ou bem-estar no trabalho assume. A idéia de realização e expressão pessoal, por exemplo, é focada na preocupação do indivíduo consigo mesmo. Tal suposição é pertinente a muitas culturas ocidentais e também parece ter sido adequada nas pesquisas realizadas no Brasil. Estudos futuros, por sua vez, deverão aprofundar cuidadosamente cada elemento constituinte das dimensões do bem-estar em diferentes culturas ou mesmo diferentes regiões do país. Variáveis sócio-demográficas, como idade, gênero, escolaridade, e variáveis relacionadas aos papéis ocupacionais deverão ser consideradas para a compreensão do fenômeno e de seus antecedentes. O campo das experiências positivas no trabalho deverá se desenvolver na medida em que novos estudos sejam conduzidos.

\section{Referências Bibliográficas}

ALBUQUERQUE, A. S.; TRÓCCOLI, B. T. Desenvolvimento de uma escala de bem-estar subjetivo. Psicologia: Teoria e Pesquisa, Brasília, v. 20, n. 2, p. 154-164, 2004.

ANTUNES, R.; ALVES, G. As mutações no mundo do trabalho na era da mundialização do capital. Educação e Sociedade, Campinas, v. 25, n. 87, p. 335-351, 2004.

BARSKY, A.; KAPLAN, S. A. If you feel bad, it's unfair: a quantitative synthesis of affect and organizational justice perceptions. J ournal of Applied Psychology, Washington, v. 9, p. 286-295, 2007.

DANIELS, K. Measures of five aspects of affective well-being at work. Human Relations, London, v. 53, p. 275-294, 2000.

DESSEN, M. C. Bem-estar pessoal nas organizações: o impacto de configurações de poder e características de personalidade. 2005. Dissertação (Mestrado em Psicologia) - Universidade de Brasília, Brasília, 2005.

DIENER, E.; EMMONS, R. A.; LARSEN, R. J.; GRIFFIN, S. The Satisfaction With Life Scale. Journal of Personality Assessment, Falls Church, v. 49, n. 1, p. 71-75, 1985.

DIENER, E.; SUH, E. M.; LUCAS, R. E.; SMITH, H. L. Subjetive wellbeing: three decades of progress. Psychological Bulletin, Washington, v. 125, p. 276-302, 1999.

ESTRAMIANA, J. L. A. Desempleo y bienestar psicológico. Madrid: Siglio XXI de España Editores, 1992. 
FERREIRA, M .C. O.; SILVA, A. P. C. E. O.; FERNANDES, H. A., ALMEIDA, S. P. Desenvolvimento e validação de uma Escala de Afetos no Trabalho (ESAFE). Avaliação Psicológica, São Paulo, v. 7, n. 2, p. 143-150, 2008.

JEX, S. M.; SPECTOR, P. E. The impact of negative affectivity on stressor-strain relations: a replication and extension. Work and stress, London, v. 10, p. 36-45, 1996.

KAHN, R. L.; BYOSIERE, P. Stress in organizations. In: DUNNETE, M. D.; HOUGH, L. M. (Orgs.). Handbookof industrial and organizational psychology. Palo Alto, CA: Consulting Psychologists Press, 1992, p. 571-650.

MASLACH, C.; JACKSON, S. Maslach Burnout I nventory Manual. Palo Alto, CA: Consulting Psychologists Press, 1986.

MOURÃO, R. G. V. O impacto da percepção de justiça organizacional no bem-estar do trabalhador de uma organização pública. 2009. Dissertação (Mestrado em Psicologia) Universidade Católica de Brasília, Brasília, 2009.

PASCHOAL, T. Bem-estar no trabalho: relações com suporte organizacional, prioridades axiológicas e oportunidades de alcance de valores pessoais no trabalho. 2008. Tese (Doutorado em Psicologia) Universidade de Brasília, Brasília, 2008.

PASCHOAL, T.; TAMAYO, A. Construção e validação da Escala de Bem-estar no Trabalho. Avaliação Psicológica, São Paulo, v. 7, n. 1, p. 11-22, 2008.

PAZ, M. G. T. Poder e saúde organizacional. In: TAMAYO, A. (Org.). Cultura e Saúde nas organizações. Porto Alegre: Artmed, 2004, p. 127-154.

PORTO, J. B. Mensuração de Valores no Brasil. In: TAMAYO, A.; PORTO, J. B. (Orgs.). Valores e comportamentos nas organizações. Petrópolis, RJ: Vozes, 2005, p. 93-119.

ROS, M. Psicología social de los valores: uma perspectiva histórica. In: ROS, M.; GOUVEIA, V. V. (Orgs.). Psicología social de los valores humanos: desarrollos teóricos, metodológicos y aplicados. Madrid: Biblioteca Nueva, 2001, p. 27-51.

RYAN, R. M.; DECI, E. L. On happiness and human potentials: a review of research on hedonic and eudaimonic well-being. Annual Review of Psychology, Palo Alto, v. 52, p. 141-166, 2001.

RYFF, C. D. Happiness is everything, or is it? Explorations on the meaning of psychological well-being. Journal of Personality and Social Psychology, Washington, v. 57, p. 1069-1081, 1989.

SAVING, L. ; ROCCAS, S.; HALEVY, N. Um novo desfio para gerentes: o papel dos valores na introdução de tecnologias inovadoras de comunicação nas organizações. In: TAMAYO, A.; PORTO, J. B. (Orgs.). Valores e comportamentos nas organizações. Petrópolis, RJ: Vozes, 2005, p. 125-144. 
SAVING, L.; SCHWARTZ, S. H. Values priorities and subjective wellbeing: direct relations and congruity effects. European J ournal of Social Psychology, New York, v. 69, p. 437-488, 2000.

SILVA, L. S. Valores organizacionais e valores humanos como fatores de impacto no bem-estar ocupacional. 2007. Dissertação (Mestrado em Administração de Empresas) - Universidade Presbiteriana Mackenzie, São Paulo, 2007.

SIQUEIRA, M. M. M.; PADOVAM, V. A. R. Bases teóricas de bem-estar subjetivo, bem-estar psicológico e bem-estar no trabalho. Psicologia: Teoria e Pesquisa, Brasília, v. 24, n. 2, p. 201-209, 2008.

SOBRINHO, S. R. Bem-estar no trabalho, clima social e estratégias de enfrentamento (coping). 2008. Dissertação (Mestrado em Psicologia) - Universidade Católica de Brasília, Brasília, 2008.

SCHWARTZ, S. H. Universals in the content and structure of values: theoretical advances and empirical teste in 20 countries. In: ZANNA, M. (Org.). Advances in Experimental Social Psychology. Orlando: Academic, 1992, p. 1-65.

. Existen aspectos universales en la estructura y contenido de los valores humanos? In: ROS, M.; GOUVEIA, V. V. (Orgs.). Psicología social de los valores humanos: desarrollos teóricos, metodológicos y aplicados. Madrid: Biblioteca Nueva, 2001, p. 53-77.

Valores humanos básicos: seu contexto e estrutura intercultural. In: TAMAYO, A.; PORTO, J. B. (Orgs.). Valores e comportamentos nas organizações. Petrópolis, RJ: Vozes, 2005, p. 21-55

TAMAYO, A. Hierarquia de valores transculturais e brasileiros. Psicologia: Teoria e Pesquisa, Brasília, v. 10, n. 2, p. 269-286, 1994.

Contribuições ao estudo dos valores pessoais, laborais e organizacionais. Psicologia: Teoria e Pesquisa, Brasília, v. 23, n. especial, p. 17-24, 2007.

TAMAYO, A.; PASCHOAL, T. A relação da motivação para o trabalho com as metas do trabalhador. Revista de Administração Contemporânea, Curitiba, v. 7, n. 4, p. 33-54, 2003.

TAMAYO, A.; SCHWATRZ, S. H. Estrutura motivacional dos valores humanos. Psicologia: Teoria e Pesquisa, Brasília, v.9, p. 329-348, 1993.

TAMAYO, M. R.; TRÓCCOLI, B. T. Exaustão emocional: relações com a percepção de suporte organizacional e com as estratégias de coping no trabalho. Estudos de Psicologia, Natal, v. 7, p. 37-46, 2002.

WARR, P. Work, happiness and unhapiness. New Jersey: Lawrence Erlbaum Associates, 2007.

WATERMAN, A. S. Two conceptions of happiness: contrasts of personal expressiveness (Eudaimonia) and hedonic enjoyment. 
Journal of Personality and Social Psychology, v. 64, p. 678-691, 1993.

WATERMAN, A. S.; SCHWARTZ, S. J.; CONTI, R. The implications of two conceptions of happiness (hedonic enjoyment and eudaimonia) for the understanding of intrinsic motivation. Journal of Happiness Studies, v. 9, p. 41-79, 2008.

WATSON, D.; CLARK, L. A.; TELLEGEN, A. Development and validation of brief measures of positive and negative affect: the PANAS scales. Journal of Personality and Social Psychology, v. 54, p. 1063-1067, 1988.

WIESE, B. S.; FREUND, A. M. Goal progressmake one happy, or does it? Longitudinal finding from the work domain. Journal of Occupational and Organizational Psychology, v. 78, p. 287-304, 2005.

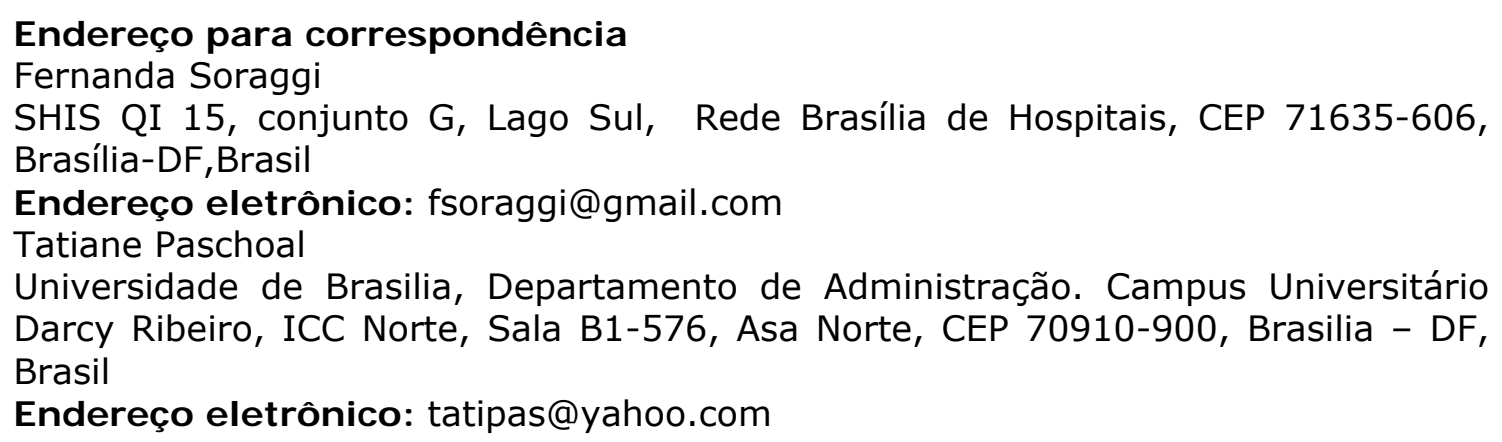

